\title{
Application of GIS to Oil and Gas Pipeline Management (A Case Study of South-South Nigeria)
}

\author{
Epuh E.E ${ }^{1, *}$, Ufot A.I ${ }^{1}$ and Orji M.J ${ }^{1}$ \\ ${ }^{1}$ Department of Surveying and Geoinformatics, University of Lagos, Lagos, Nigeria \\ Corresponding Author: *eepuh@yahoo.com
}

\begin{abstract}
Over the years, the oil and gas industries have been engaging in traditional practices and procedures in their mode of operation in pipeline management. This has brought some draw backs in terms of planning and mapping of pipeline facilities. Several challenges in terms of natural disaster, equipment failure, and human error could not be averted because the traditional methods could not produce survey maps and plans required for "real time "applications. The advent of Geographic Information System (GIS) technology in the oil and gas industries has brought about rapid changes and improvements in the activities of the oil and gas industries in terms of exploration, production and transmission of products from the field to the end users. In this research, digital maps showing oil and gas pipelines as well as other relevant features such as terrain, vegetation and settlements within the study area were generated. A relational database model was developed using pipeline attributes such as; the pipeline diameter, date of installation, pressure, coating and soil type. Queries on the database provided the required information such as; the required date of maintenance of pipes, areas prone to sabotage, areas with specific pipe diameters in various sections, previous spillages and the affected areas.
\end{abstract}

Keywords: GIS, pipeline management, oil and gas, remote sensing, south-south

\subsection{Introduction}

Oil and Gas Pipelines are of great significance to the Nigerian economy. According to Nnah and Owei (2005), the petroleum pipeline is an essential mode of transportation and is an infrastructure of a highly specialized nature. Petroleum pipeline network presently measures over 7,000km in Nigeria (Agbazie, 2004; Nigerian National Petroleum Cooperation, 2002)). Petroleum pipelines in Nigeria traverse the whole extent of the country's geo-political zones, ranging from swamp forest and rain forest to savannah grass lands, and are exposed to diverse climatic and soil conditions, with varying consequences including leakages and seepages of petroleum products, with damaging implications for communities and the environment (Agbazie, 2004; Ekwo, 2011). Most of the pipes run across rivers, creeks, swamps and farmland in the Niger Delta, an environment that is wetland fragile, and highly sensitive to stress (Ogon, 2006). Pipelines are part of the major infrastructure of oil and gas production. They are necessary for the transportation, storage and marketing of natural gas, crude oil, and refined petroleum products. Though, most of the pipelines are buried underground, they can still pose a threat to human beings, wildlife and the environment as a whole. Unlike some other modes of transportation, such as roads, pipelines do not improve access for people living in the communities through which they pass. Rather, they impose constraints on interactions and, when located close to houses, constitute a hazard to life. Ogwu (2011) argues that even when a pipeline is no longer in use it is left to rust in the open field as the oil companies are not willing to pay the cost of dismantling it. After the construction phase, there is usually a lack of periodic monitoring. Graham and Thrift (2007) emphasized the importance of repair and maintenance in modern society, but lamented that this is usually overlooked. They underscore the way the culture of repair and maintenance has helped to sustain the activities of electricity and communication as well as auto-mobility. Monitoring is an important activity to ensure the integrity of pipelines and the safety of people in the vicinity. Roper and Dutta (2005) presented several GIS and remote sensing applications for pipeline security assessment. With the advance of modern computing technology and storage devices, the ability to capture new forms of data at a more rapid pace is feasible. Roper and Dutta (2005) go further to identify thermal imaging as useful for pipeline detection primarily 
because it offers the ability to distinguish pipelines at night, due to temperature differences between pipelines and the ground. This separates it from other optical sensors, which typically are only able to reveal useful information during the day with proper daylight, and with good weather (i.e., low cloud cover). Another application for GIS in pipeline security is in visualization and mapping. Visualizing and managing pipelines in GIS mapping systems can be very valuable in comparison with viewing information in tabular format. "The ability to visualize pipeline features has proven to be a powerful tool for decision-makers - saving valuable time and resources" (Clemonds \& Isaacs, 2010).

However, the safety of oil and gas infrastructure from vandalization events is critical to quality, healthy and safe environment, Brume (2007). Blackouts and oil embargos are also a consequence of infrastructure attacks (Farrell, 2004). Whereas oil companies attribute most spillages to sabotage, the communities argue that they are as a result of structural failure of the pipeline and consequent leakages (Ekwo, 2011). Some estimates put the potential oil revenues lost to spillage and theft over the past two years in Nigeria at close to $\$ 11$ billion US dollars (Reuters, Nigeria Loses \$10.9B to Oil Theft, 2013). Offshore oil rigs are at risk for pirate attack and ransom, with several reported cases taking place in Nigeria. GIS is a tool that has the ability to assist. Oil spillage involves the leakage of crude oil from pipelines. When there is an oil spill on water, spreading immediately takes place. The gaseous and liquid components evaporate, some get dissolved in water and even oxidize, and yet some undergo bacterial changes and eventually sink to the bottom by gravitational action. The soil is then contaminated with a gross effect upon the terrestrial life. As the evaporation of the volatile lower molecular weight components affect aerial life, dissolution of the less volatile components with the resulting emulsified water affects aquatic life other pipeline problems.

Other sources of concern in oil spillage are natural disasters due to earth movement, fire, flood and the neglect of the Oil and gas producing communities. It is difficult to prevent these types of events without knowing where the infrastructure is located. GIS and spatial analysis can assist by helping to predict where these attacks will occur in the future. This helps in contributing to a reduction in future attacks, as well as an improvement in response time once an attack or theft does take place. The objective of this paper is to use GIS as a tool for monitoring the status of oil and gas pipeline network from a central monitoring system in order to enhance pipeline integrity check i.e.-to help pipeline managers minimize the cases of pipeline system failure, loss and respond swiftly if there is any. To identify sources of pipeline leakages and reduce response time so as to act promptly in dealing with them in case of pipeline emergencies without any danger to lives, property and the environment. To further evaluate the requirements for the real-time monitoring of pipeline network, making it possible for pipeline managers to monitor every aspect of the network from the comfort of a central base station.

\subsection{Pipeline Management}

The Pipeline network forms one of the most critical and intelligent components of the petroleum industry. The creation and management of a functional pipeline network requires in depth analysis and study of geographical locations, requirements and managed utilization of resources leading into optimal productions and transfer of crude and refined oil from petroleum reserves to refinery and then to storage units respectively. GIS as a support system for linear infrastructure management. GIS technology can play a decisive role in promoting economically and socially feasible solutions to the existing spatial problems of infrastructure management. This can be done by using GIS to collect the variety of information on the infrastructure and integrating this into a process for monitoring, and evaluating the infrastructure networks. GIS technology has the capacity to integrate and customize the spatial features needed for the management of the linear infrastructure.

\subsubsection{Methods of Pipeline Management}

There are several methods of pipeline management. It includes:

\section{a) Physical Method}

Gas pipeline monitoring could be done regularly by posting security personnel to physically monitor the pipelines on foot or by vehicles and Aircrafts to patrol the Pipeline Right of Way (PROW) and avert any deliberate damage to the pipelines by vandals. This method is effective for stopping the incessant attacks on pipelines. 


\section{b) Mechanical Method}

i. SCADA: The term "SCADA" is defined as Supervisory Control and Data Acquisition is used to perform monitoring and control tasks required for pipeline operation from a remote station. It runs on UNIX platform and has distributed system architecture. The various system components such as operator workstations, database servers and main/stand-by computers are connected to a redundant Local area Ethernet Network. SCADA among other things can be used to monitor properties of the gas such as gas flow rate, temperature and pressure at different times that could determine the state of the gas. This method appears to be the most viable option as it involves the monitoring of pipelines in "Real-Time". It is done from a Central Control Station. At the 1998 GIS/Remote Sensing Conference in Toronto, Canada, Fung et al. (1998) posited that remotely sensed data such as aerial photographs and satellite imageries could be used to monitor pipelines periodically. Real- time pipeline monitoring model uses special sensor described as "black boxes" in this study. A black box is a hardware that integrates dial-up connection (phone system) using Satellite Communication System and computing power in a single low-profile housing. The black boxes are installed at strategic points along the pipelines to be monitored. Gas properties such as gas flow rate; temperature and pressure measured in the network by the SCADA (Supervisory Control and Data Acquisition System) equipment are transmitted as data packets to the Central Monitoring Station through the dial-up network where it can be monitored, recorded and analysed Data logged in the black boxes and uses a laptop computer to download the data. Polling is done by placing a short call lasting only a few seconds to the phone system in the black box. The whole monitoring systems is designed with a high level of intelligence to allow the black box to selectively transmit its position and other data when a special user-defined event occurs rather than periodically transmitting data throughout the day. These event reports provide much more specific data for pipeline monitoring and management while significantly reducing Communication costs.

The geographic co-ordinates of the boxes acts as a spatial databases because the accurate knowledge of the position of each of the black boxes will be helpful to the pipeline mangers during emergencies. To make pipeline monitoring more versatile, a back-up communication system should be available to provide a secured and reliable alternative communication path in the event of primary system failure for example, if a failure occurs in the primary dial-up communications system, a back-up dial-up/ satellite communication system should be provided to maintain SCADA communication from the central monitoring system to pipeline remote terminal stations.

ii. Poly Pigging: Pigging in pipeline maintenance can be defined as the process, by which cleaning is carried out in pipeline. However, the use of polyethane pigs is used in this process. Pigging of pipes not only provides cleaner pipe-contents, but also increases flow. This means added life and greater efficiency for pipes and lower overall costs. In the long run, poly pigs come in a wide variety of styles (drying, wiping, scraping) to accommodate almost any application, such as oil and gas transmission, municipal water, petro-chemical, pulp and paper mine slurry and fire sprinkler systems. Pigs clean as well as they do because of their design. Each job requires careful selection of the pigs to be used to ensure desired results.

Poly Pigs have the ability to negotiate short radius bends, reduced port valves and multi-dimensional piping. They effectively have no distance limitations depending on the selection, design and material being cleared from the pipe. They have the capability to travel up to two thousand miles. The pigs form a "sliding seal" in the pipe and when pressure is applied the polyethane bands try to expand causing a scraping action. Because of this sealing and scraping action, they remove product build-up foreign matter and loose sediment. It increases the carrying capacity of the pipeline, improve product quality, conserve energy and power by reducing pump pressure and flow integrity

\subsubsection{Geographic Information System (GIS) Approach to Pipeline Management}

GIS technology facilitates the organization and management of data with a geographic component. It also eases data acquisition and utilization. GIS provides the pipeline operator with improved capability to manage pipeline integrity, improved efficiencies in pipeline operations, and improved response to business development opportunities. Competitive pressure and regulatory constraints are placing increasing demands on pipeline operators to operate in an efficient and responsible manner. Responding to these demands requires accessibility to information regarding geographically distributed assets and 
operations. Cova (1999) states that GIS is gaining in favour in comparison with traditional methods of risk assessment. Several studies have used GIS to assess and model risk from a spatial perspective relevant to oil pipeline projects (Cova, 1999; Cutter, 2000; Greiving, 2006; Collins, 2009). Managing pipeline from a geographic viewpoint allows users a better way to assess assets and recognize possible dangers or hazards. One of the core functionalities of GIS is mapping, and thus the difficulty of implementing this type of solution in asset management is inherently low.

For most operators, alignment sheets are the mainstay for reference to pipeline facilities manually drafted many years ago, these alignment sheets are often out of date and pose a threat to operational integrity. Bringing the alignment sheets up to date is major project requiring validating existing information, acquiring new information, and drafting the updated alignment sheets. Using GIS or a hybrid GIS/CAD system can greatly reduce the time and money required to perform this task. GIS technology offers intelligent storage, management, and presentation of facility information, right-ofway data, and other data.

With the rapid expansion of communal cities in the construction of residential buildings commercial buildings in business areas, and with the increase of industries, oil companies thus need to provide monitoring services by laying the oil pipelines and various equipment. This application requires a map to show the system of oil production pipelines and users with detailed accuracy through modern technology to search and promptly use the information.

Therefore, this application utilizes the GIS system to gather all relevant information on oil pipelines along with other useful information, to display the following:

i. Map of oil production pipelines system, sumps and equipment showing information on all related details.

ii. Cross section map of every street at various intervals to show the path and depth of the oil pipeline network and other utilities.

iii. Map showing the location of piping equipment and various flow stations.

iv. Details of oil network pipelines, for example, type, size, depth, construction contract number, date of installation, road surface, etc.

v. Map showing locations of buildings and residential areas of fuel users along with details of the gas users such as license number of fuel user, size of gas meter, etc.

vi. Information on population in the area.

The gathering and storing of information in the GIS system will enhance the efficiency of the pipeline network maintenance and benefit the communal cities. The GIS system is beneficial to the implementation of oil industry in the following ways in engineering; enable network analysis of the structural flow of oil in the oil processing pipelines at various points thus benefiting management. In request for connection to the oil pipeline, by knowing only the address of the fuel user, map of the pipelines will display whether a main pipeline exists or not in the area, thus consideration can be made instantly for the connection to the service pipes. Monitor and promptly repair cracks and leaks of pipeline, because the map clearly depicts the details of the pipe location, for example, type, depth, pipe age, road conditions, enabling accurate and prompt preparation of repair equipment and planning. Provide an overview of the information from all sides, including pipeline systems, number of communities and other, for their analysis and investment plans.

GIS can be used in the site location process to minimize impacts to the environment during construction and from accidental release, as well as to lessen the costs of permits and liability risks associated with accidental releases. Ecological variables developed from publicly available spatial data sets can be utilized in this process. The themes and variables used as input in this process mainly address direct construction costs and pipeline efficiency once the pipeline has been completed. Some of the variables include: shortest distance from source to market, least grading (removal of trees, etc.), costs associated with right of way, slope of terrain, number of stream, road, and railroad crossings, substrate (rock, soils, 
etc., associated with burial), existing laws and regulations (wetlands, etc.), proximity to population centers and utilization of existing utility corridors and easements.

\subsection{Coverage Analysis}

The potential costs of environmental impacts during construction as well as ecological and liability costs that may result from accidental releases after construction also accounts to the cost factor of the petroleum company. Some of these costs can be substantial (potentially millions of dollars) and include: environmental damage, litigation and settlement costs, environmental response and investigation, criminal and civil penalties, environmental remediation, damage to reputation and community relations, An increasing number of environmental spatial data sets have become available to the general public, offering a great opportunity for companies to avoid these environmental and liability risks with relatively little effort by incorporating them into their normal GIS setting procedures.

GIS technology facilitates the organization and management of data with a geographic component. It also eases data acquisition and utilization. GIS provides the pipeline operator with improved capability to manage pipeline integrity, improved efficiencies in pipeline operations, and improved response to business development opportunities.

\subsection{Methodology}

\subsection{Data Creation and Conversion}

In any GIS implementation, the creation of attribute and spatial data is of great importance. Since GIS is computer based, the spatial and attribute data used has to be converted to digital format if it is not digital already. Spatial data is created by digitizing and scanning methods. For this project, the following procedures were adopted for creating the spatial data for the pipeline network in the study area i.e. south-south Nigeria (see Figure 1). Scanning was done by conversion of an analogue map to a digital map using a raster data structure format. A raster data structure format is a cellular based structure in which data is stored sequentially by rows and columns of a group of gridded cells called pixels. Each cell or group of cells must be rectangular and also represent a feature.

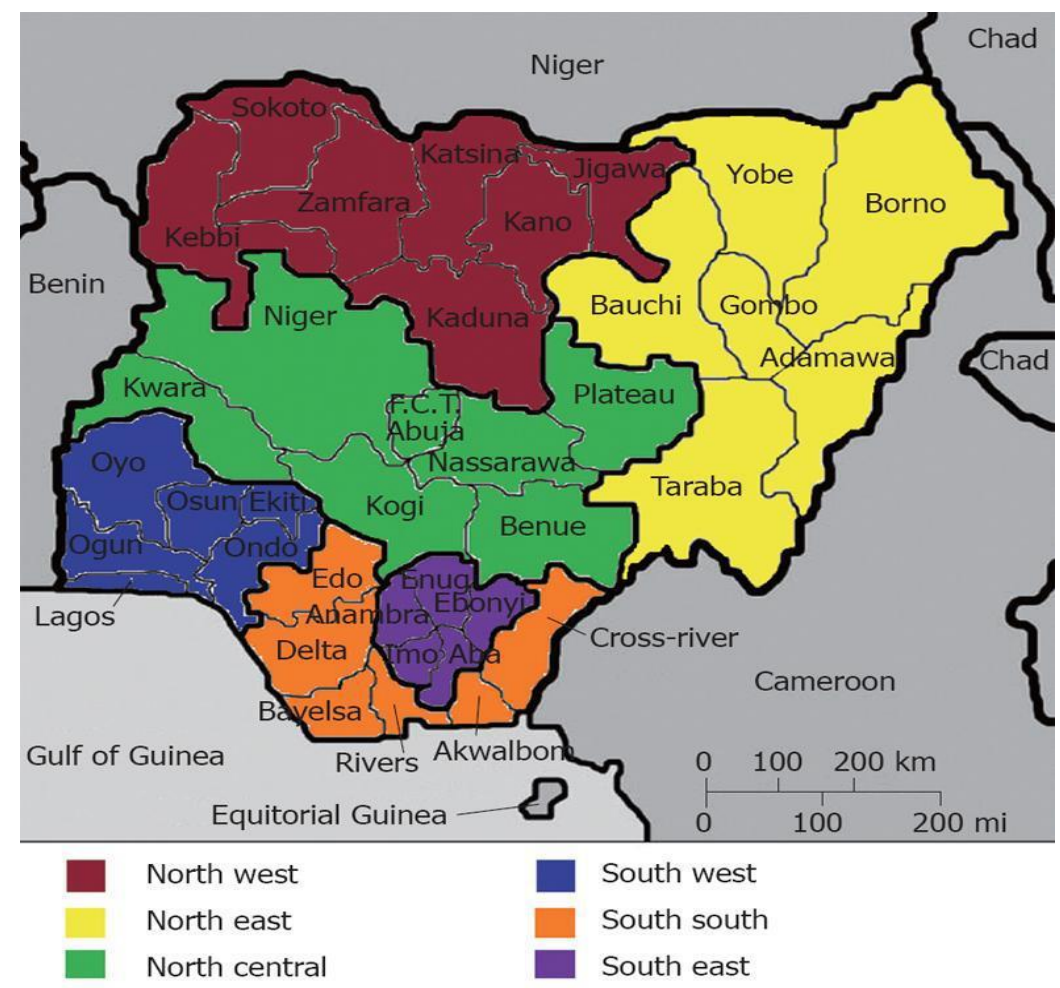

Figure 1: Map of Nigeria showing the south-south region (Source: World Journal Cardiology, 2012) 


\subsection{Attribute Database Structure}

To create an attribute data in GIS, firstly, a database file was first created and saved in a database format such as database IV format in Microsoft Excel before linking it to objects in a GIS software. However, some GIS software allows you to enter your database directly in it. For this study, the database was entered directly into Arc GIS.

A relational database model was used in this study to build the attribute database structure. These database tables have a "key" which associates (relates) the data to a particular entity. This key serves as a unique facility identifier or equipment identifier, or the key may be positional such as a line identifier and station location on that line. This positional identification was utilized for data such as pipe specification (wall thickness, coating type, etc.) Techniques for defining the tables to hold this data are well established.

A sample of the attributes used for each of the fields and their different keys includes the followings:

- $\quad$ Road (RoadID, Road Type, Length, PipeID) Primary Key is RoadID and the Foreign Key is PipeID.

- $\quad$ Settlement (SettleID, State, Local government area, PipeID) Primary Key is SettleID and the Foreign Key is PipeID.

- $\quad$ River (RiverID Area, RiverType, PipeID) Primary Key is RiverID and the Foreign Key is PipeID.

- $\quad$ Pipe (PipeID, Length, Diameter, Pressure, Temperature, Flow-rate) where PipeID is both the Primary Key and the Foreign Key.

\subsection{Query in GIS Environment}

A total pf seven queries were performed in GIS environment for the pipelines and these include:

\section{Query 1}

The Control Monitoring Station department of Mobil producing company in Nigeria found out that some pipelines have malfunctioned due to equipment failure. In this query, Arc GIS was used to detect the pipelines susceptible to failures by comparing the installation date with the date that maintenance was last carried out and the present date.

\section{Query 2}

A pipeline explosion has occurred and information has been sent to the occupants in the affected area. Due to the pipeline hazard within that region, the area is being left unfertile and unusable for local farmers and they desire to move to the nearest suitable location to carry out their occupation of farming. In this query, the occupants want to obtain information relating to the nearest location that is most conducive for agricultural use.

\section{Query 3}

In this case, we wish to determine, from the incident mentioned above, the townships of the affected settlements and the terrain-geology, soil type and soil structure to enable the pipeline managers get to the location with the most appropriate equipment and transportation.

\section{Query 4}

An inside source from the Niger Delta has revealed that angry youths wish to carry out a demonstration by busting oil pipes as they have done in the past. In this query, we can predict the likely location of the next from existing database. From available data, the highest value for number of occurrence is 8 thus; the location with this record can be noted.

\section{Query 5}

This query is performed to determine the locations of the various pipeline sizes and their coating. This will aid the channelization of pipeline network to reduce the work load of each pipe. 


\section{Query 6}

This query is performed to locate a pipeline leakage on the map. The parameters that indicate occurrence of leakages include the tolerance limit set for pressure and flow rate measurements in pipes.

\section{Query 7}

This query is performed to determine the abnormal rise in temperature due to frictional force between the pipe contents (oil and gas flowing through the pipe) and the pipeline itself. Given the standard tolerance limit of pipes not greater than $4022^{\circ} \mathrm{C}$.

\subsection{Results and Discussion}

Results of the seven queries are shown in Figures $2-11$. Query 1 in Figures $2 \& 3$, Query 2 in Figure 4, Query 3 in Figures $5 \&$ 6, Query 4 in Figure 7, Query 5 in Figures $8 \&$ 9, Query 6 in Figure 10, and Query 7 in Figure 11.

In Query 1, prediction data or period was carried out for routine maintenance of pipelines. It was observed that data update could easily be achieved due to the flexibility of the ArcView software used for this research work. An example to display this was shown in the query. The date of installation for a pipe was July 1976 and November 1975 while the date it was last maintained was February 1982. From the database of the pipeline, the date of next maintenance is displayed as well as the location of the pipe and other relevant data on the map (highlighted in yellow). Therefore, prediction of routine maintenance can be carried out by regularly checking the database for the pipes and updating them when needed.

The spillage of oil due to blowout or sabotage can greatly affect the condition of the environment where such has occurred. Due to the oil spill that occurred as seen in Query 2 which made the location very unfertile for agriculture, the occupants, notably farmers, desire to move to the nearest fertile environment to carry out agriculture. Therefore, the query was made to obtain the nearest fertile area or communities taking note of vegetation type and agricultural use.

Results of Query 4 showed areas that are prone to pipeline attacks by vandals. The security requirements of these are should be more using both physical and mechanical processes. In the distribution of pipelines, various sizes and coating are used because of market requirement and the effect of geology on the pipes. Query 5 shows part of the pipeline network with 24inches diameter and also part of the pipeline network with mastic coating.

In any pipeline operation to determine a leakage in a pipe, some of the factors considered include the valve ID (valve identification), flow rate of pipe contents, pressure in pipe etc. Determination of leakages is dependent on the decrease or increase in flow rate as well as increase or decrease in pressure. A sample check is carried out to determine an increase in flow rate and a decrease in pressure, taking to note that the sample testing of the Niger Delta pipeline allows tolerance limit for normal flow rate measurement range of 170-250psi. A decrease or increase in this would signify a pipeline leakage. Likewise, pressure ranges from 170-300psi. Any increase or decrease would be suspected for a pipeline leakage.

The examples in queries 6 and 7 to detect leakage are such that a pipe was shown to have a flow rate measurement of $265.004 \mathrm{~m}^{3}$ while the pressure was measured as $168.000 \mathrm{~N} / \mathrm{m}^{2}$. The query automatically displayed the pipes involved as well as their location and other relevant data on the map by highlighting the particular pipes and their attributes in yellow. 


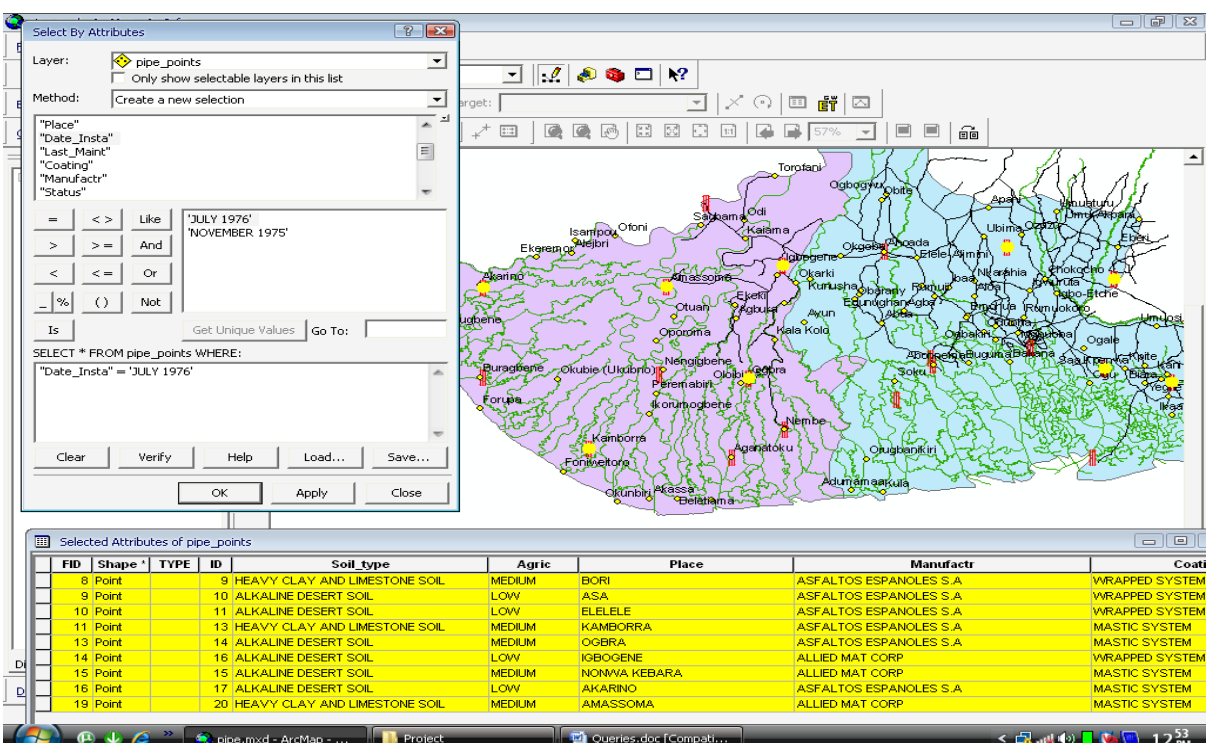

Figure 2: Query Showing areas installed in July 1976

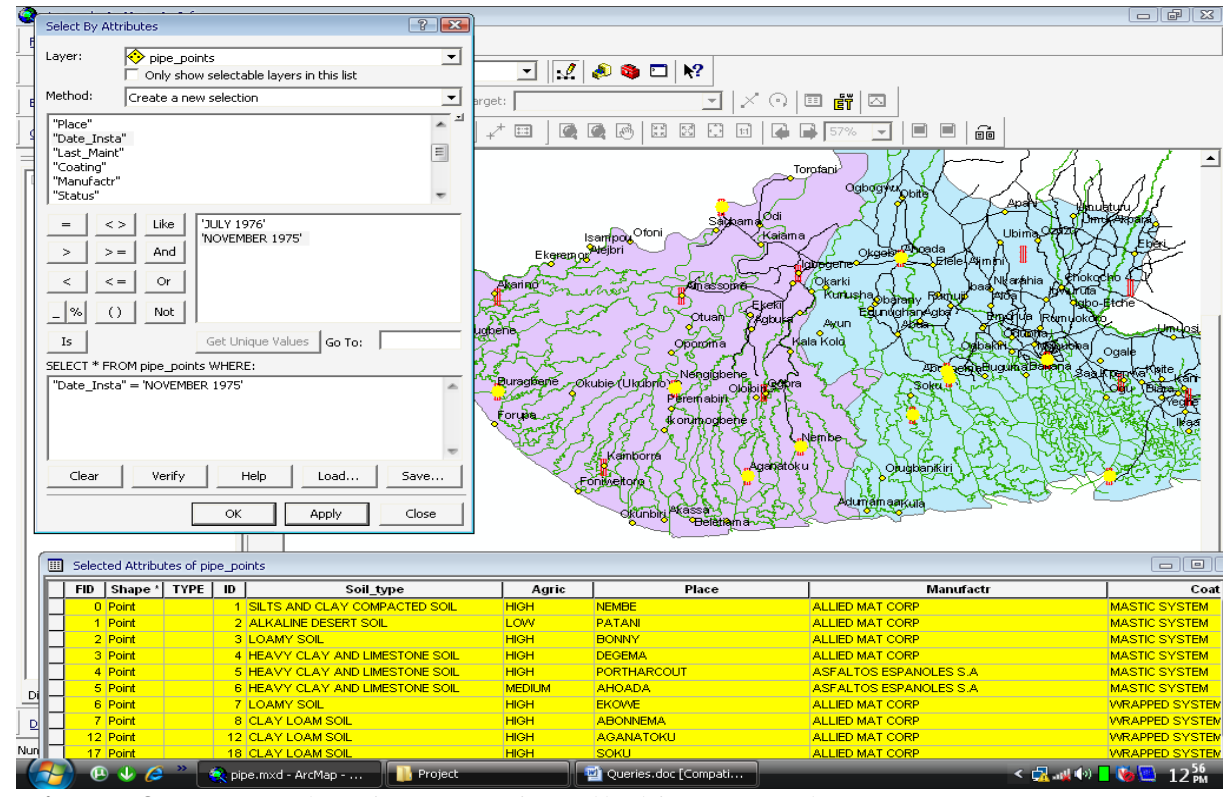

Figure 3: Query Showing areas installed in November 1975

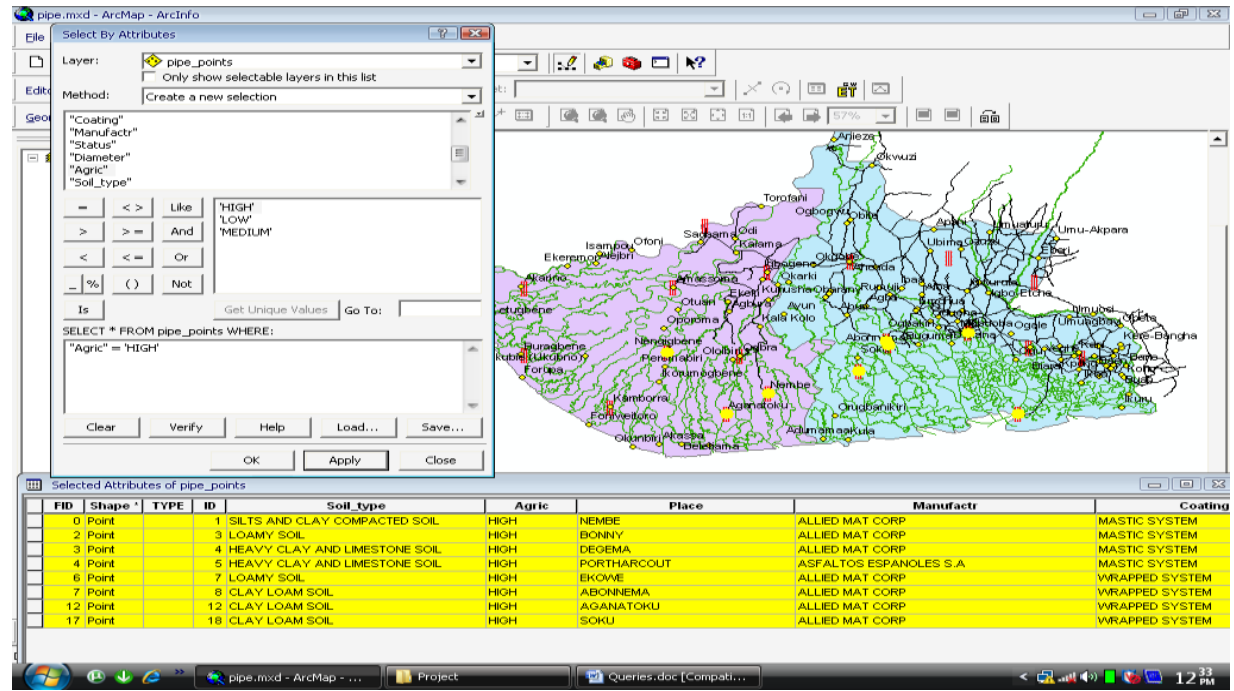

Figure 4: Query showing areas conducive for Agriculture 


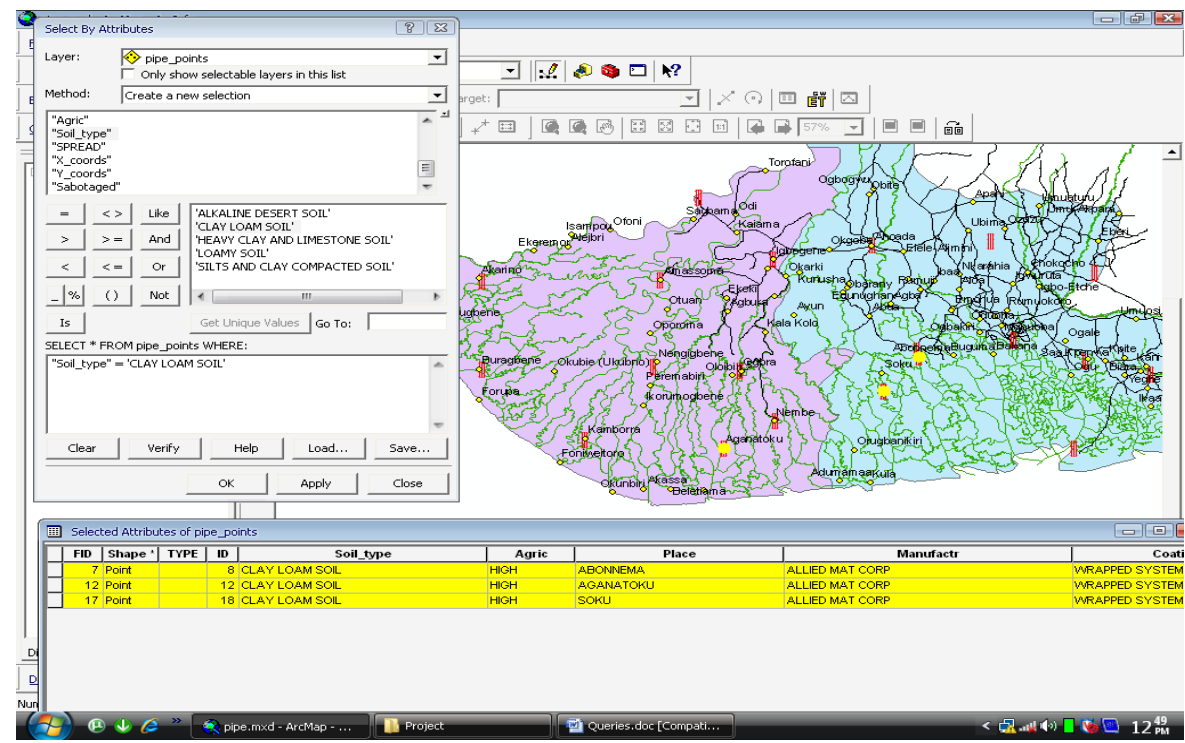

Figure 5: Query showing areas with Clay loamy soil.

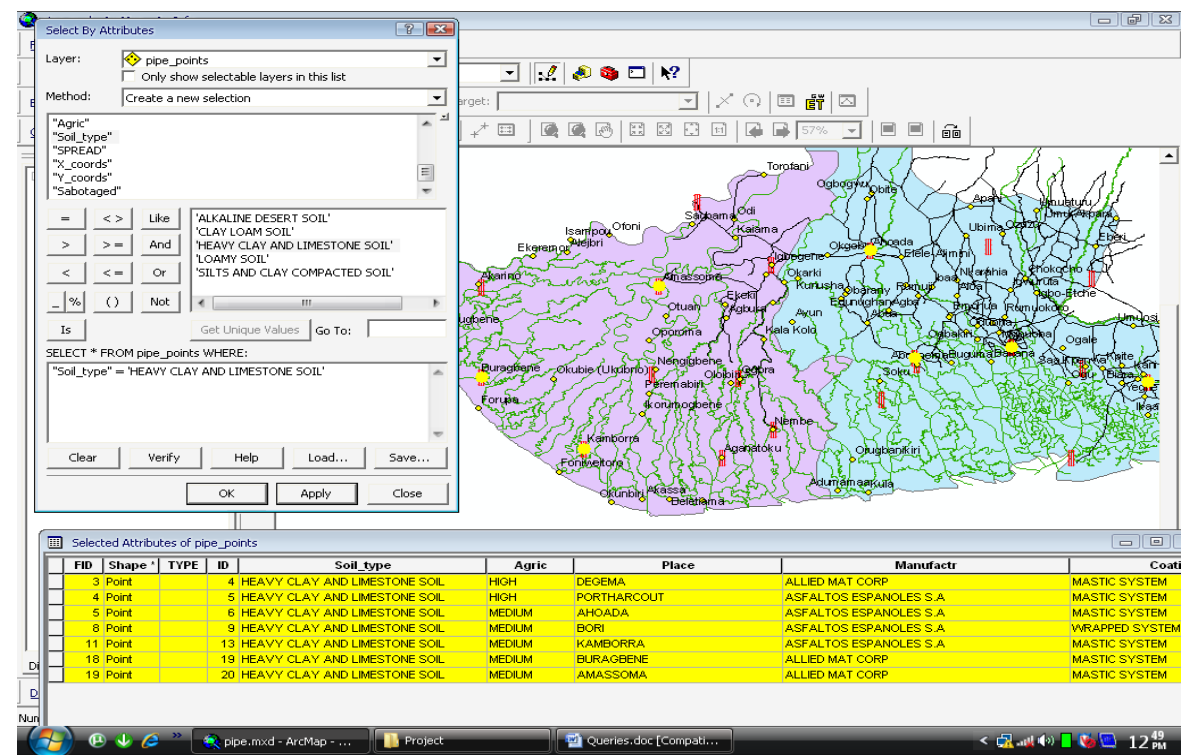

Figure 6: Query showing areas with Heavy clay and Limestone

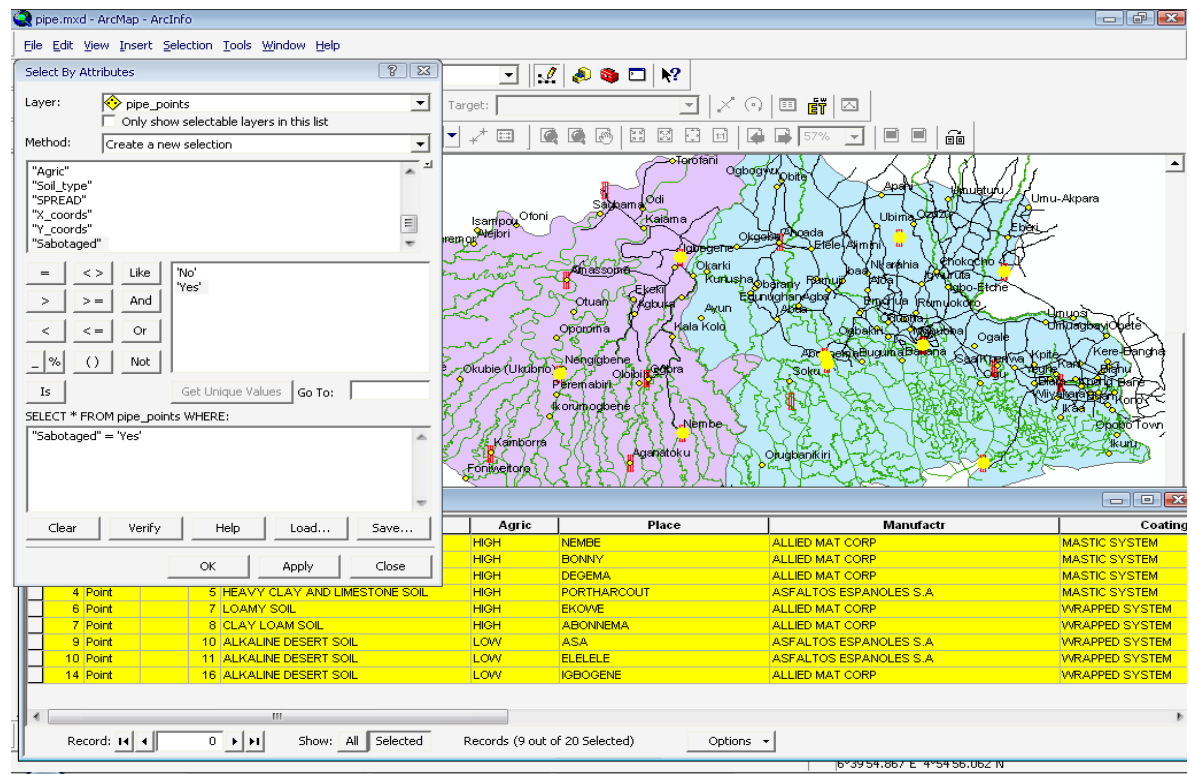

Figure 7: Query showing areas prone to sabotage 


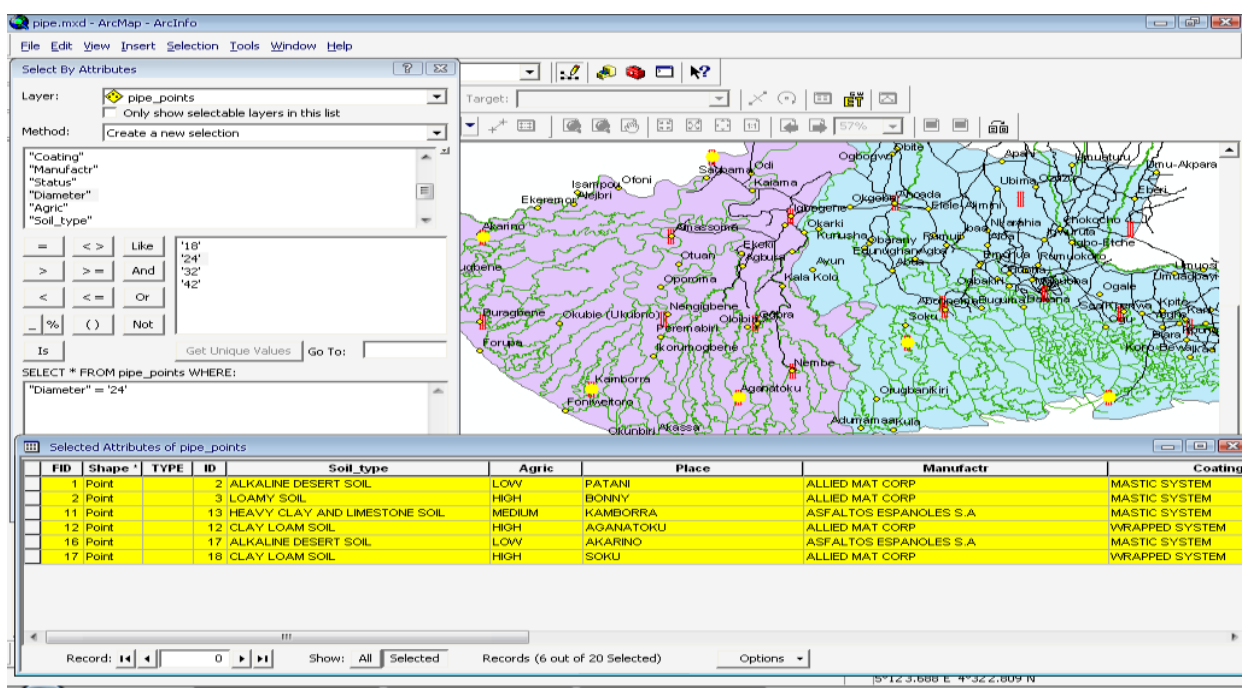

\section{Figure 8: Query showing Pipeline with 24 inches Diameter}

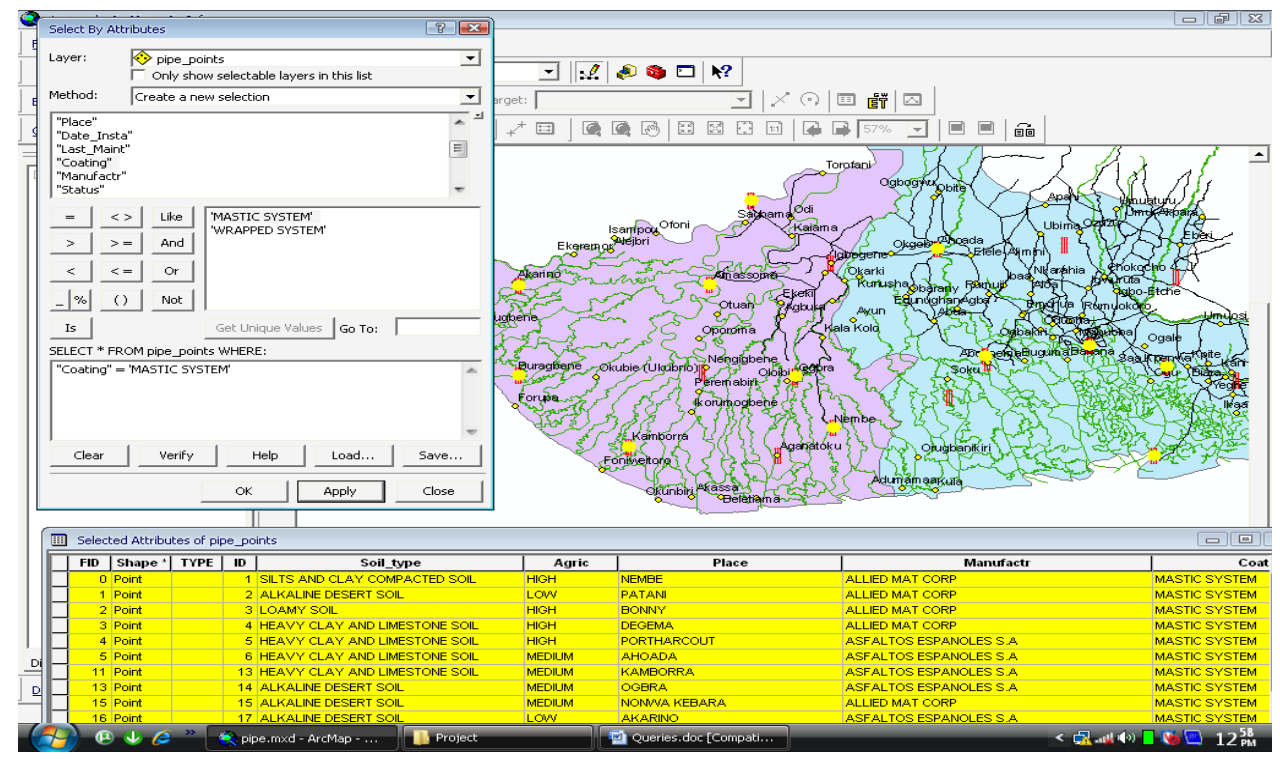

Figure 9: Query Showing pipes covered with mastic coating

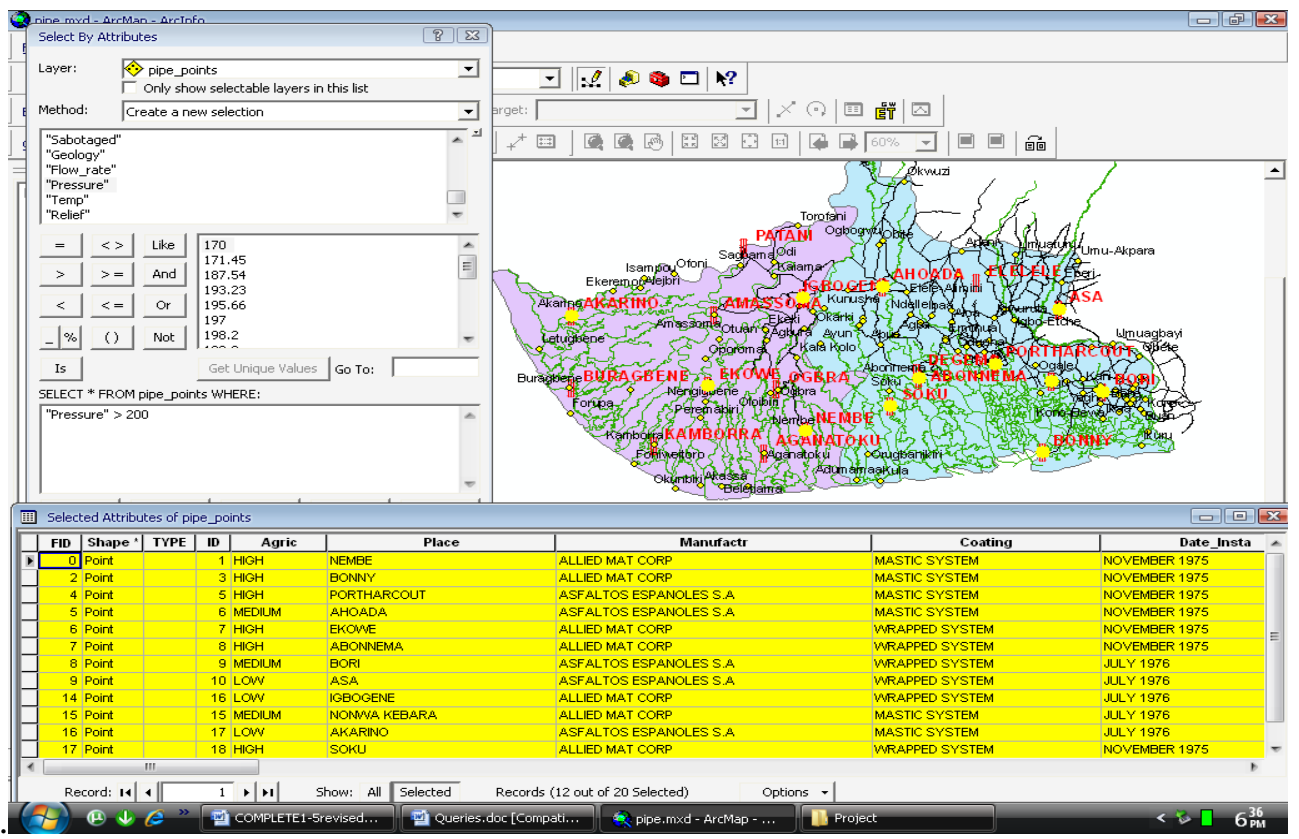

Figure 10: Query showing pipelines with pressures above 200psi 


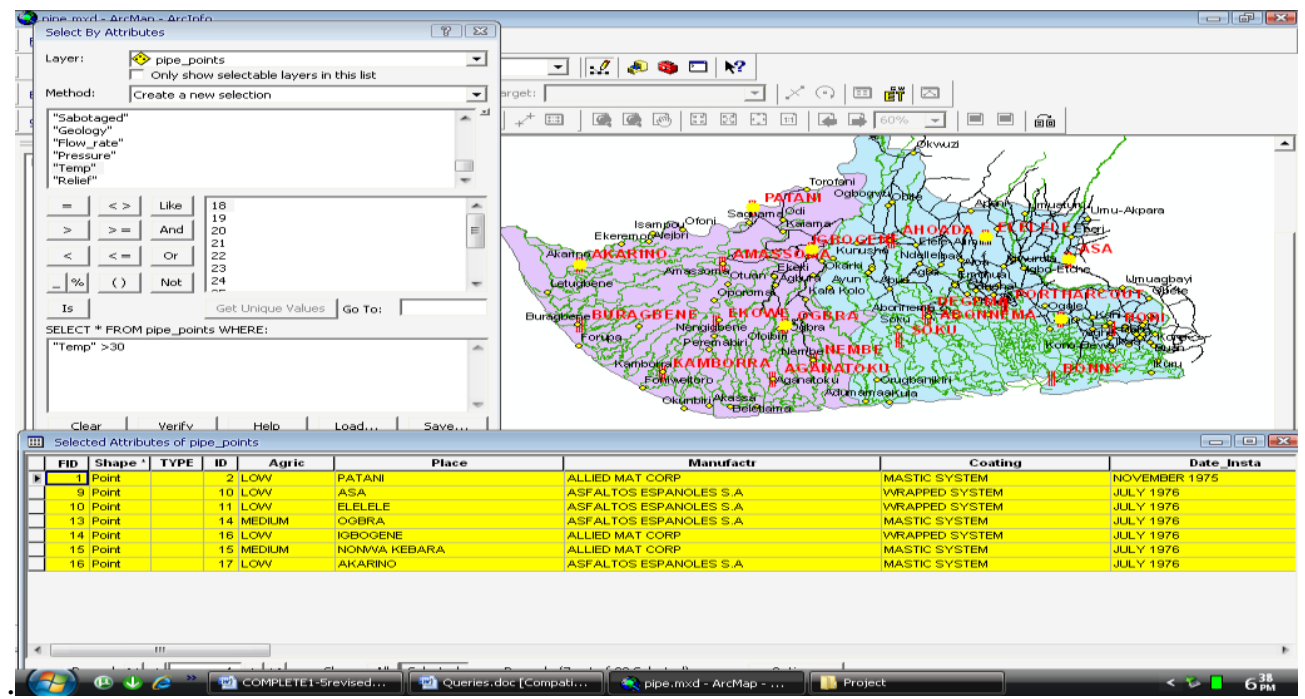

Figure 11: Query showing pipelines with temperature above $30^{\circ} \mathrm{C}$

\subsection{Conclusion}

GIS can be used to simulate networks, create maps and link images with attributes to better enable decisions and actions to be taken quickly. The development of databases and automation of record keeping among others enhance the planning and implementation of GIS for effectively monitoring the status and condition of pipelines from a central monitoring station. Application of GIS in pipeline management is an efficient and cost effective that must be developed to ensure that oil and gas industries acquire high safety standards, reduce risk to the environment and also reduce response time during pipeline emergencies.

\section{Acknowledgement}

The authors thank ExxonMobil Nigeria Unlimited for the release of the data used in this research.

\section{References}

Agbazie, K. N. (2004) Petroleum Pipeline Leakages in Pipelines and Product Marketing Company Report for Chief Officers Mandatory Course 026, Lagos.

Brume F. (2007). Oil pipelines Vandalism in the Niger Delta Region: The Way Out ${ }^{\text {e }}$ [Online]. Available at: http://www.waado.org/Environment/Brume (Accessed: 13/10/2007).

Clemonds, M. A., \& Isaacs, R. (2010): GIS in Pipeline Management. Retrieved from Building Design and Construction: http://www.bdcnetwork.com/gispipeline-management

Collins, T. G. (2009): Vulnerability to environmental hazards in the Ciudad Juarez (Mexico)-El Pas (USA) metropolis: A model for spatial risk assessment in transnational context. Applied Geography, $29,448-461$.

Cordner, L. (2011): Managing regional risk: offshore oil and gas safety and security in the Asia-Pacific region. Australian Journal of Maritime and Ocean Affairs, 15-24.

Cova, T. (1999): GIS in emergency management. In P. Longley, M. Goodchild, R. David, \& D. Maguire, Geographical Information Systems: Principles, Techniques, Applications, and Management (pp. 845-858). West Sussex, England: Wiley.

Cutter, S. M. (2000): Revealing the Vulnerability of People and Places: A Case Study of Georgetown County, South Carolina. Annals of the Association of American Geographers, 90(4), 713-737. 
Ekwo, U. S. (2011): Newcastle University “Collaboration-Based Management Of Petroleum Pipeline Rights Of Way In Nigeria". (February, 2011)

Fung, R.B; Fraser D.W and R.P Gauthier (1998): “Application, of Remote Sensing Data for monitoring Gas Pipeline Row" (published in proceedings of 1998 GIS/Remote Sensing Conference. Toronto Ontario, Canada). (pp 401-404).

Farrell, A. Z. (2004): Energy Infrastructure and Security. Annual Review of Environment and Resources, 29, 422-460.

Fowler, R. (2000, March): The Low Down on LIDAR. Earth Observatory Magazine,

Graham, S and Thrift, N (2007) Out of Order Understanding Repair and Maintenance. tp://tcs.sagepub.com/content/24/3/1 The online version of this article can be found at: DOI: $10.1177 / 0263276407075954$.

Greiving, S. F. (2006): A Methodology for an Integrated Risk Assessment of Spatially Relevant Hazards. Journal of Environmental Planning and Management, 49, 1-19.

Nigerian National Petroleum Corporation (2002). The Nigerian National Petroleum Corporation as presented to the Bureau of Public Enterprises Abuja, Nigeria: NNPC.

Nnah, W.W. and Owei, O.B. (2005) "Land Use Management Imperative for Oil and Gas Pipeline Nework in Nigeria". Abuja. Nnah, W.W. and Owei, O.B. (2005) "Land Use Management Imperative for Oil and Gas Pipeline Network in Nigeria". Abuja.

Ogon, E.K. (2006) Natural resource abundance in Nigeria: from dependence to development. Resources Policy, 33, 168-174.

Ogwu, F. A (2011): Challenges of Oil and Gas Pipeline Network and the role of Physical Planners in Nigeria. FORUM Ejournal 10 (June 2011): 41-51. Newcastle University, School of Architecture, Planning and Landscape University.

Roper, W. and Dutta, S. (2005). Remote Sensing and GIS Applications for Pipeline Security Assessment. ESRI User Conference Proceedings, (p. 24). San Diego, CA.

Reuters. (2013, July 30). Nigeria Loses $\$ 10.9 \mathrm{~B}$ to Oil Theft. Retrieved from Fin 24: http://www.fin24.com/Economy/Nigeria-loses-109bn-to-oil-theft-20130730

World Journal Cardiology, (2012). Blood pressure, prevalence of hypertension and hypertension related complications in Nigerian Africans: a review, 4(12), 327. 